\title{
Defining the optimal mixture composition of geopolymers based on the coal mine waste and the shale.
}

\author{
Natalia Paszek ${ }^{1, *}$, and Marcin Górski ${ }^{1}$ \\ ${ }^{1}$ Silesian University of Technology, Faculty of Civil Engineering, Department of Structural Engineering, Akademicka 5, 44-100 Gliwice, \\ Poland
}

\begin{abstract}
Nowadays, industry plays one of the main roles in daily life. Extractive industry is one of the oldest industries, present in almost each country. Unfortunately, besides the benefits connected with development of the extractive industry, there are also disadvantages such as enlarging amounts of stored industrial wastes. One of the ideas how to manage with unnecessary wastes is geopolymer, relatively new material which parameters are similar to the parameters of the concrete. The paper shows the following attempts to define optimal mixture composition of geopolymer based on the wastes from the coal mine and geopolymer based on the shale from the post-mining spoil tip. Coal mine waste, shale, powdered glass waste, metakaolin and sand were used as the raw materials. Sodium hydroxide and sodium silicate were used as activators. Mixtures consisting of mentioned components used in different ratios were prepared and poured into small moulds. The compressive strength of samples was tested after 3, 5 and 7 days. From the best mixture, the bigger samples of dimensions $4 \times 4 \times 4 \mathrm{~cm}$ were prepared and tested after 7 and 14 days. The paper presents characteristics of used wastes, preparation and curing processes, test procedure and finally, compressive strengths and densities of tested geopolymers.
\end{abstract}

\section{Introduction}

Mining is a sector of the industry which plays an important role in many countries. During the mining process, particular geological materials are extracted from the earth. Unfortunately, the valuable minerals state frequently only a small part of extracted material. The rest of material which is useless for further works is called industrial wastes or tailings. Such wastes are stored in different ways in dependence on the kind of waste. Mine tailings which are in slurry form are often disposed in impoundments. They can be also disposed in underground mines or used as open-pit backfilling [1]. In the Upper Silesia (Poland) mining wastes are often stored in form of spoil-tips.

Independently on the kind of wastes and on their storage system, many problems arise around this matter. The first thing is the cost of the storage or disposal of wastes. There are also many environmental problems such as possibility of air, water and ground water pollution [1]. The possible propagation of stored wastes can as well state the important issue [1]. Questions arising around the problem of industrial wastes motivate scientists to look for the solutions. Recycling of the tailings is one of the possible ideas how to solve the problem of waste's storage. One of the branches of industry which enable reuse of wastes is building engineering. Many types of wastes (fly ashes, slags) can be used as the addition to the concrete. Wastes can partly replace the cement, lower the cost of materials and influence in positive way the properties of the mixture [2]. Although, the addition of particular wastes to the concrete mixture is well known and commonly used procedure, the wastes state only a small part within the rest of compounds.

Partly as the response to the problem of unnecessary wastes and partly because of the need for new solutions there came into existence the idea of geopolymer - the building material based almost entirely on the industrial wastes. Geopolymer is a type of a binder produced as the effect of polymeric reaction of the silicon and the aluminium materials (raw materials) with the alkaline liquids (activators). The raw material can be a material of geological origin or by-product in form of industrial wastes [3]. Geopolymer can be not only a building material which allows recycling tailings but it can also help in lowering $\mathrm{CO}_{2}$ emission to the environment [4].

The concept "Geopolymers" contains the wide range of materials. Many types of geopolymers have been already tested in the past but there are still many mixtures and new types of wastes to be checked. The paper presents initial tests performed on the two new types of geopolymers. The main goal of the research was to define the optimal mixture composition for these two geopolymers.

\section{Preliminary tests}

\subsection{Composition of the mixtures}

Corresponding author: natalia.paszek@polsl.p1 
Table 1. Detailed composition of mixture no 1 based on the waste from the coal mine.

\begin{tabular}{|c|c|c|c|c|c|c|}
\hline Mixture & Waste [g] & Glass [g] & Metakaolin [g] & $\begin{array}{c}\text { Sodium silicate } \\
\text { [g] }\end{array}$ & $\begin{array}{c}\text { Sodium } \\
\text { hydroxide }[g]\end{array}$ & Water [g] \\
\hline M-I-1 & 80 & 20 & 0 & 55 & 15 & 15 \\
\hline M-I-2 & 40 & 10 & 10 & 35 & 10 & 0 \\
\hline M-I-3 & 30 & 20 & 5 & 35.25 & 10.61 & 0 \\
\hline M-I-4 & 50 & 5 & 5 & 40 & 10 & 0 \\
\hline M-I-5 & 50 & 0 & 0 & 36.6 & 10 & 0 \\
\hline
\end{tabular}

Table 2. Detailed composition of mixture no 2 based on the shale.

\begin{tabular}{|c|c|c|c|c|c|c|}
\hline Mixture & Waste [g] & Sand $[g]$ & Glass [g] & Metakaolin [g] & $\begin{array}{l}\text { Sodium silicate } \\
{[\mathrm{g}]}\end{array}$ & $\begin{array}{c}\text { Sodium } \\
\text { hydroxide [g] }\end{array}$ \\
\hline M-II-1 & 40 & 0 & 10 & 10 & 35 & 10 \\
\hline M-II-2 & 40 & 0 & 10 & 10 & 25 & 5 \\
\hline M-II-3 & 10 & 15 & 2.5 & 2.5 & 7.5 & 5.2 \\
\hline M-II-4 & 25 & 37.5 & 6.25 & 6.25 & 18 & 13 \\
\hline M-II-5 & 37.5 & 25 & 6.25 & 6.25 & 16 & 11.27 \\
\hline M-II-6 & 31.25 & 31.25 & 6.25 & 6.25 & 16 & 11.6 \\
\hline M-II-7 & 50 & 12.5 & 6.25 & 6.25 & 16 & 12.28 \\
\hline M-II-8 & 25 & 31.25 & 12.5 & 6.25 & 16 & 11 \\
\hline M-II-9 & 37.5 & 37.5 & 0 & 0 & 16.3 & 10.5 \\
\hline M-II-10 & 31.25 & 25 & 12.5 & 6.25 & 16.57 & 12.1 \\
\hline
\end{tabular}

Two basic types of mixtures were used during the tests. First mixture, denoted as M-I, was based on the dust waste from the coal mine located on the Upper Silesia in Poland. Aside from the waste, the powdered glass and metakaolin were used as the raw materials in the first mixture. Solutions of sodium silicate and sodium hydroxide were used as activators. To the mixture M-I-1 the water was also added. The water is not needed in mixture for polymerization process [3] and it is rather avoided. The M-I-1 was the first mixture to be prepared and it had not been known yet how much liquid is needed to make mixture workable and to enable putting it into the mould. The waste from the coal mine occurred more absorbable than it was initially assumed. The water was used to asses how much more activators should be added to the next mixtures to ensure proper consistency.

The second mixture, denoted as M-II, was based on the red shale from the post-mining spoil tip from Gliwice (Upper Silesia, Poland). Sand of particle diameter less than $1 \mathrm{~mm}$, powdered glass and metakaolin were used as the rest of the raw materials. As in the case of the first mixture, the sodium silicate and sodium hydroxide were used as activators.

\subsection{Mixture preparation process}

\footnotetext{
*Corresponding author: natalia.paszek $@$ polsl.pl
}

Each single mixture from M-I-1 to M-II-10 was prepared separately. Firstly all dry components (raw materials) used in particular mixture were batched and mixed together in the plastic box. Then, the activators (sodium silicate and sodium hydroxide) were mixed together in proper amounts. Activators were being mixed for 5 minutes in the metal vessel put on the vibrating table. After all mixing processes, the raw materials were added into the vessel with activators and mixed energetically with a hand stirrer. When mixture achieved homogenous consistency, it was poured into the longitudinal moulds of height and width equal to $2,5 \mathrm{~cm}$ and compacted. Prepared samples were put into the oven at temperature $60^{\circ} \mathrm{C}$ for 24 hours. After this time, samples were kept in the ambient temperature until the day when there were subjected to compressive strength test. Before the test, longitudinal samples were cut into the small cubes of side dimension approximately $2,5 \mathrm{~cm}$.

\subsection{Observations on cured samples}

From the very beginning the difference in behaviour between the geopolymer mixture based on the waste from the coal mine and between the mixture based on the shale from the spoil tip was noticeable. In the case of the first mixture, the polymerization process was very fast. After mixing of all components, mixture became viscous 
and workable. Placing it into the moulds and compacting did not state a problem. However, after few minutes, the workability of the mixture decreased considerably causing problems during compacting process. After curing in the oven for 24 hours, samples produced from the first mixture became hard and there was no problem in demoulding. The second mixture, based on the shale, obtained less viscous consistency. It was definitely more liquid than the first mixture. The process of polymerization was slower too. Even after 24 hours in the oven, the process of polymerization was not completed and samples were not ready to be demoulded.

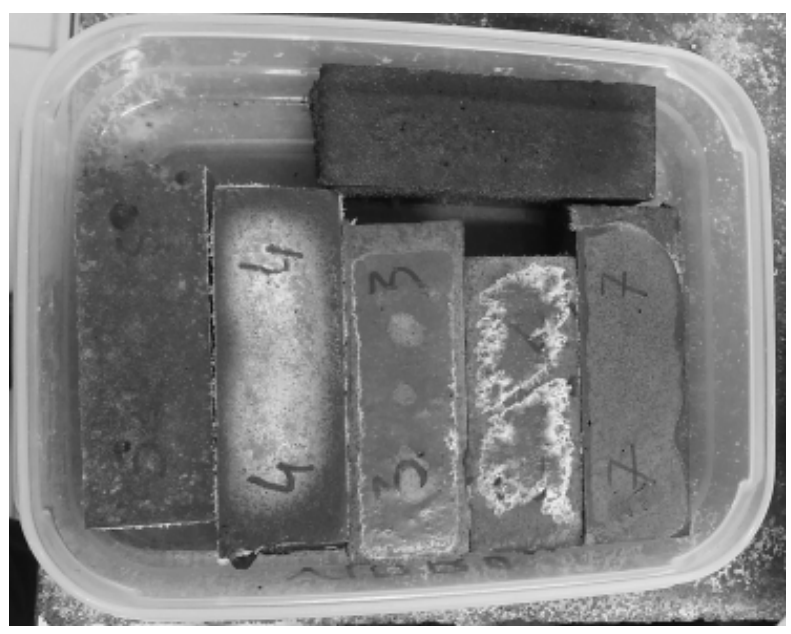

Fig. 1. The efflorescence visible on the samples.

After the 24 hours in the temperature of $60^{\circ} \mathrm{C}$, samples were taken out from the oven and left in the ambient temperature. During the curing process in the ambient temperature, the efflorescence effect was noticed on the part of the samples. The efflorescence is called the effect of the formation of white salt deposits on the surface of sample. The main reason for the efflorescence growth is the presence of sodium cations [5]. The efflorescence on the samples prepared from the first mixture (based on the coal mine waste) was minimal. It appeared on the side surfaces of the samples in form of partly changes in colour. The efflorescence did not enlarge in time. In the case of the second type of mixture (based on the shale), the efflorescence was much more significant although its intensity varied between particular samples. In the case of mixtures M-II-1, M-II4, M-II-10 the efflorescence was almost negligible it appeared in form of partly changes in colour on the top surface of samples. In the case of mixtures M-II-2, M-II6, M-II-8 and M-II-9 there was the small efflorescence in form of changes of colour and some visible white crystals.

In mixtures M-II-5 and M-II-7 the efflorescence was the most significant. Almost whole top surface of the samples was covered in big, white crystals. In the samples on which the efflorescence effect appeared, it was enlarging in time.

The effect of the efflorescence on the geopolymer samples based on the shale can be seen in the Figure 1. The picture was taken 48 hours after preparing the mixture. The numbers visible in the picture are divergent with the numbers of mixtures from the Table 2.

\subsection{Compressive strength tests}

The compressive strength of geopolymer samples was tested on ADR Touch 3000 BS EN Compression Machine. Two or three samples were prepared from each mixture. Samples were tested after 3 or 5 and 7 days. The first stage of test was a trial one. Tests were performed to check which mixtures are most promising so the time of tests was not strictly fixed.

Table 3. Compressive strength of the geopolymer based on the wastes from the coal mine.

\begin{tabular}{|c|c|c|c|c|}
\hline \multirow{2}{*}{ Mixture } & \multicolumn{4}{|c|}{ Compressive strength after } \\
\cline { 2 - 5 } & $\begin{array}{c}\text { 3 days } \\
\text { [MPa] }\end{array}$ & $\begin{array}{c}\text { 5 days } \\
\text { [MPa] }\end{array}$ & \multicolumn{2}{|c|}{ 7 days [MPa] } \\
\hline M-I-1 & 9.00 & - & 8.10 & 9.20 \\
\hline M-I-2 & 19.00 & - & 22.50 & - \\
\hline M-I-3 & - & - & 18.23 & 17.26 \\
\hline M-I-4 & - & - & 16.57 & 17.46 \\
\hline M-I-5 & - & 15.36 & 13.69 & - \\
\hline
\end{tabular}

Table 4. Compressive strength of the geopolymer based on the shale.

\begin{tabular}{|c|c|c|c|c|c|}
\hline \multirow{2}{*}{ Mixture } & \multicolumn{4}{|c|}{ Compressive strength after } & \multirow{2}{*}{$\begin{array}{c}\text { Density } \\
\text { [kN/m }\end{array}$} \\
\cline { 2 - 5 } & $\mathbf{5}$ days [MPa] & \multicolumn{2}{|c|}{ 7 days [MPa] } & \\
\hline M-II-1 & 8.96 & 9.30 & 9.10 & - & - \\
\hline M-II-2 & 15.56 & - & 11.29 & - & - \\
\hline M-II-3 & - & - & 12.53 & - & - \\
\hline M-II-4 & - & - & 11.15 & 11.80 & 17.77 \\
\hline M-II-5 & - & - & 12.99 & 11.75 & 18.48 \\
\hline M-II-6 & - & - & 10.27 & 10.57 & 18.85 \\
\hline M-II-7 & - & - & 16.20 & 14.06 & 18.50 \\
\hline M-II-8 & - & - & 12.40 & 13.92 & 18.61 \\
\hline M-II-9 & - & - & - & - & 17.88 \\
\hline M-II-10 & - & - & 13.38 & 13.51 & 18.53 \\
\hline
\end{tabular}

The mixture M-II-3 was the first mixture with addition of the sand and only one sample was made to check if addition of the sand does not disturb polymerization that is why there is only one result from this test. Samples produced from the mixture M-II-9 were not strong enough to be tested in the machine so compressive strength of these samples was not measured. 


\subsection{Conclusions from the initial tests.}

Samples made of mixture M-I-2 (based on the waste from the coal mine) obtained the highest compressive strength. This mixture contained $60 \mathrm{~g}$ of raw materials ( $40 \mathrm{~g}$ of waste, $10 \mathrm{~g}$ of powdered glass and $10 \mathrm{~g}$ of metakaolin) and $45 \mathrm{~g}$ of activators (35g of sodium silicate and $10 \mathrm{~g}$ of sodium hydroxide). The compressive strength of this mixture was the highest among all tested mixtures both after 3 days (19.0MPa) and after 7 days $(22.5 \mathrm{MPa})$. Except of the mixture M-I-1 (which contained water), all mixtures based on the waste from the coal mine obtained better compressive strengths than mixtures based on the shale from the post-mining spoil tip. It means that the waste from the coal mine is more promising material. From the geopolymer mixtures of the second type, the best compressive strength achieved mixture M-II-7 (16.20MPa and 14.06MPa). Unfortunately, this result is still not impressive and it was decided not to continue tests with this mixture. As it was mentioned before, the lowest compressive strength achieved mixture M-II-9. It was possible to crush the samples with fingers. This mixture as the only one did not contain powdered glass or metakaolin within raw materials. It means that these components improve the process of polymeryzation and improve the compressive strength.
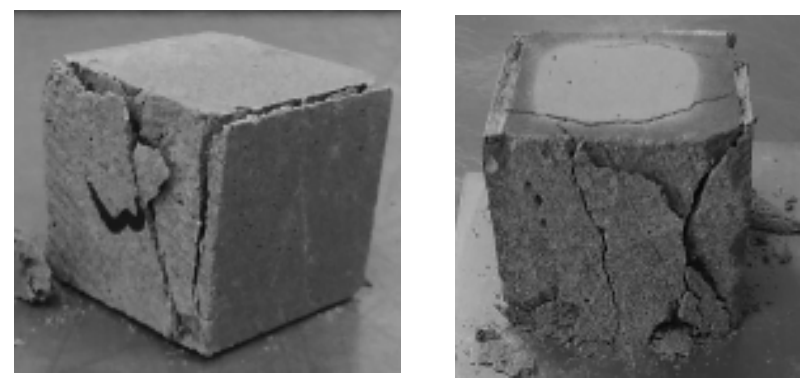

Fig. 2. The cracking pattern on broken samples.

Samples prepared on the base of both mixtures broke in similar way. The first cracks appeared on the top surface, near the edge and on the edge surfaces (Fig. 2). After test, the edges of destroyed samples fell apart. Not destroyed core of the samples had shape of two connected cones (Fig. 3). Such a scheme of destruction is similar to the way in which concrete samples are broken during compressive strength tests [2]. Broken geopolymer samples based on the coal mine waste were much more compacted than the shale based geopolymer samples. The broken parts of the second geopolymer

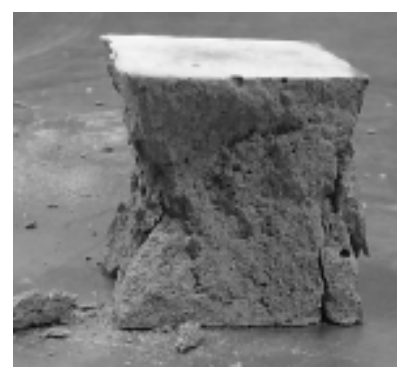
type, were crushed and the powdered particles were falling from the inside of crushed samples (Fig. 4). That means that inside the geopolymer based on the shale, process of polymerization was not completed.

Fig. 3 The core of the broken geopolymer sample based on the coal mine waste.

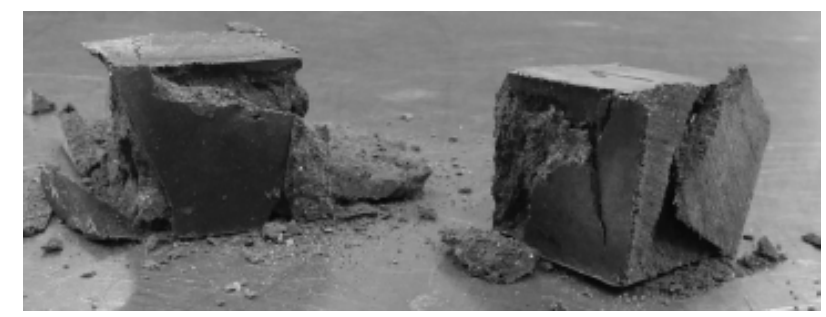

Fig. 4. The crushed inside of the shale based geopolymer samples.

The average density of geopolymer based on the shale with the addition of the sand was equal to $18.37 \mathrm{kN} / \mathrm{m}^{3}$. The differences in measured densities were small. The highest density was equal to $18.85 \mathrm{kN} / \mathrm{m}^{3}$, the lowest was equal to $17.77 \mathrm{kN} / \mathrm{m}^{3}$. The density of geopolymer based on the shale is lower than the density of the normal weight concrete which should range from 22 to $26 \mathrm{kN} / \mathrm{m}^{3}$ [2]. Although, the density of geopolymer based on the shale is lower than the density of normal weight concrete, it is relatively high in comparison to lightweight concretes which densities range from 13.5 to $19.0 \mathrm{kN} / \mathrm{m}^{3}$ [2]. Simultaneously, the compressive strength of samples made with the second type mixture is too low to fulfil the requirements for structural lightweight concrete minimal compressive strength which should not be lower than $17 \mathrm{MPa}$ [2]. On the other hand, this type of geopolymer is not competitive with low density concrete for non structural purposes which density should range between 3 and $8 \mathrm{kN} / \mathrm{m}^{3}$ [2].

To sum up, the mixture M-I-2 was chosen as the optimal composition from all tested mixtures for further tests on the bigger, proper size samples. The geopolymer based on the coal mine waste occurred to be promising while the further initial tests should be performed in the future to look for the optimal composition of geopolymer based on the shale.

\section{Final tests}

\subsection{Composition of the chosen mixture}

The mixture M-I-2 was chosen as the best one which achieved the highest compressive strength. The same composition of mixture was used for further tests. The grater amounts of components were needed for final tests because more samples were prepared. Table 5 presents final amounts of all ingredients of chosen geopolymer mixture.

Table 5. Detailed composition of chosen mixture M-I-2

\begin{tabular}{|c|c|c|c|c|}
\hline $\begin{array}{c}\text { Waste } \\
\text { [g] }\end{array}$ & $\begin{array}{c}\text { Glass } \\
\text { [g] }\end{array}$ & $\begin{array}{c}\text { Metakaolin } \\
\text { [g] }\end{array}$ & $\begin{array}{c}\text { Sodium } \\
\text { silicate } \\
\text { [g] }\end{array}$ & $\begin{array}{c}\text { Sodium } \\
\text { hydroxide } \\
\text { [g] }\end{array}$ \\
\hline 340 & 85 & 85 & 297.5 & 85 \\
\hline
\end{tabular}




\subsection{Mixture preparation process}

Mixture was prepared in the same way as the trial mixtures (process described in point 2.2.) till the moment of mixing of raw materials and activators which were mixed with special automatic mixer this time. After mixing, the geopolymer mortar was poured into six moulds of dimensions $4 \times 4 \times 4 \mathrm{~cm}$. Moulds were sprinkled with the liquid petroleum jelly before, to enable easy demoulding of samples. After pouring, the mixture was compacted, covered with the foil and put into the oven at temperature $60^{\circ} \mathrm{C}$ for 24 hours. Then, samples were took out from the oven, demoulded and kept in ambient temperature till the compression strength tests.

After demoulding, the little white strip of efflorescence appeared near the top surface of the samples. The efflorescence did not enlarged in time.

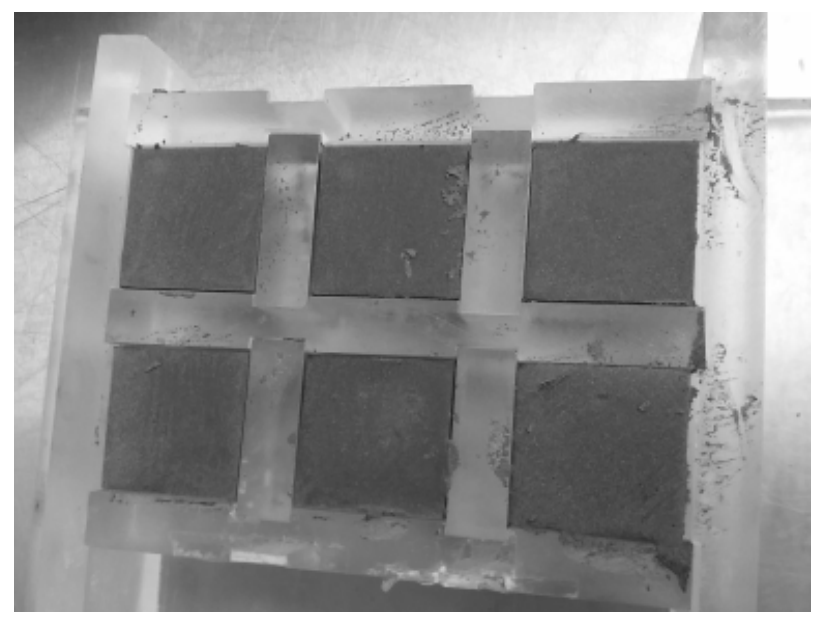

Fig. 5. Samples in moulds.

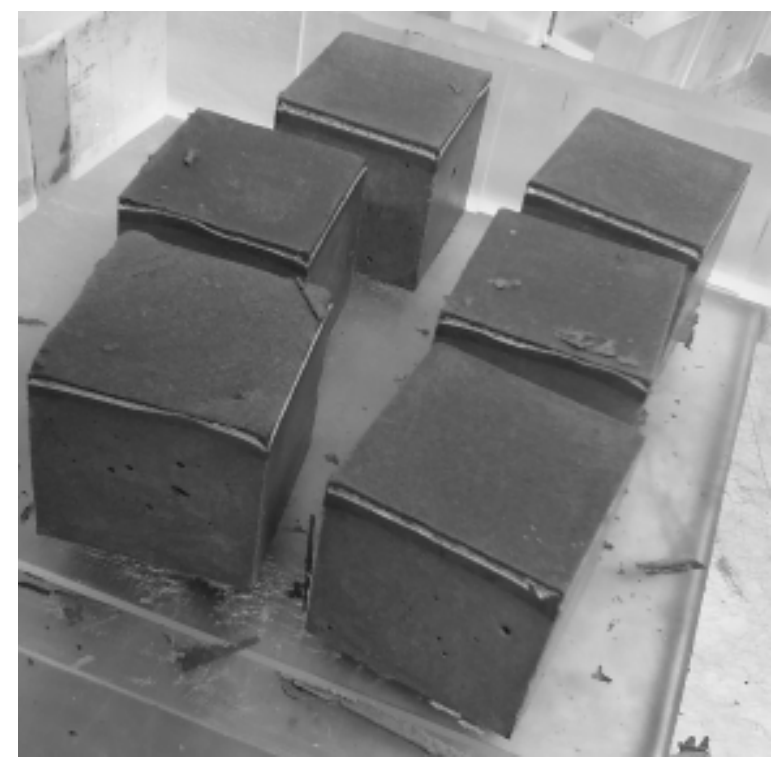

Fig. 6. The efflorescence on the demoulded samples.

The consistency of the mixture was viscous but stiff. The geopolymer mortar was workable but it lost workability very quickly. Almost immediately after pouring all six samples, it was not possible to work with the rest of the mixture which retained in the metal vessel. It means that process of polymerization started very quickly. After one hour in the oven, the samples were utterly hard.

\subsection{Compressive strength tests}

Like during the initial tests, the compressive strength of geopolymer samples was tested on ADR Touch 3000 BS EN Compression Machine. Three samples were tested after 7 days and three after 14 days. There were also measured the densities of all samples. Tests results are presented in Table 6 and Table 7.

Table 6. Compressive strength of the chosen geopolymer mixture based on the wastes from the coal mine after 7 days.

\begin{tabular}{|c|c|c|c|}
\hline \multirow{2}{*}{ Sample } & \multicolumn{2}{|c|}{$\begin{array}{c}\text { Compressive strength after } \\
\text { 7 days }\end{array}$} & \multirow{2}{*}{$\begin{array}{c}\text { Density } \\
{\left[\mathbf{k N} / \mathbf{m}^{\mathbf{3}}\right]}\end{array}$} \\
\cline { 2 - 3 } & Force [kN] & $\begin{array}{c}\text { Strength } \\
{[\mathbf{M P a}]}\end{array}$ & \\
\hline G1 & 39.39 & 24.60 & 14.40 \\
\hline G2 & 40.94 & 25.27 & 14.11 \\
\hline G3 & 41.49 & 25.93 & 14.23 \\
\hline $\begin{array}{c}\text { Mean } \\
\text { value }\end{array}$ & $\mathbf{4 0 . 6 0}$ & $\mathbf{2 5 . 2 7}$ & $\mathbf{1 4 . 2 5}$ \\
\hline
\end{tabular}

Table 7. Compressive strength of the chosen geopolymer mixture based on the wastes from the coal mine after 14 days.

\begin{tabular}{|c|c|c|c|}
\hline \multirow{2}{*}{ Sample } & \multicolumn{2}{|c|}{$\begin{array}{c}\text { Compressive strength after } \\
\text { 14 days }\end{array}$} & \multirow{2}{*}{$\begin{array}{c}\text { Density } \\
{\left[\mathbf{k N} / \mathbf{m}^{3}\right]}\end{array}$} \\
\cline { 2 - 4 } & Force [kN] & $\begin{array}{c}\text { Strength } \\
{[\mathbf{M P a}]}\end{array}$ & \\
\hline G4 & 41.84 & 26.10 & 14.40 \\
\hline G5 & 40.50 & 25.30 & 14.31 \\
\hline G6 & 40.30 & 25.20 & 14.09 \\
\hline $\begin{array}{c}\text { Mean } \\
\text { value }\end{array}$ & $\mathbf{4 0 . 8 8}$ & $\mathbf{2 5 . 5 3}$ & $\mathbf{1 4 . 2 7}$ \\
\hline
\end{tabular}

\subsection{Conclusions from the final tests.}

Mean value of compressive strength of samples was equal to $25.27 \mathrm{MPa}$ after 7 days and $25.53 \mathrm{MPa}$ after 14 days. These results are good and promising. They confirm initial results obtained on small samples. What is important, the obtained values of compressive strength are repeatable. The standard deviation of compressive strength of samples tested after 7 days is 0.7 . The standard deviation of compressive strength of samples tested after 14 days is 0.5 . What is significant, between compressive strength of samples tested after 7 days and samples tested after 14 days is only $1 \%$ of difference. The process of polymerization is fast and geopolymers 
often achieve their final compressive strength in first hours of curing [3]. Such behaviour is dissimilar to the behaviour of concrete which compressive strength increase during first 28 days considerably [2].

The compressive strength of tested geopolymer based on the waste from the coal mine can be compared with the concrete $\mathrm{C} 20 / 25$ which cubic compressive strength is equal to $25 \mathrm{MPa}$ [6].

The way of destruction of samples was similar to the destruction of the trial samples. The first cracks appeared on the sides of tested sample or on the edge of side and top surface. The not broken core of sample had shape of two connected cones.

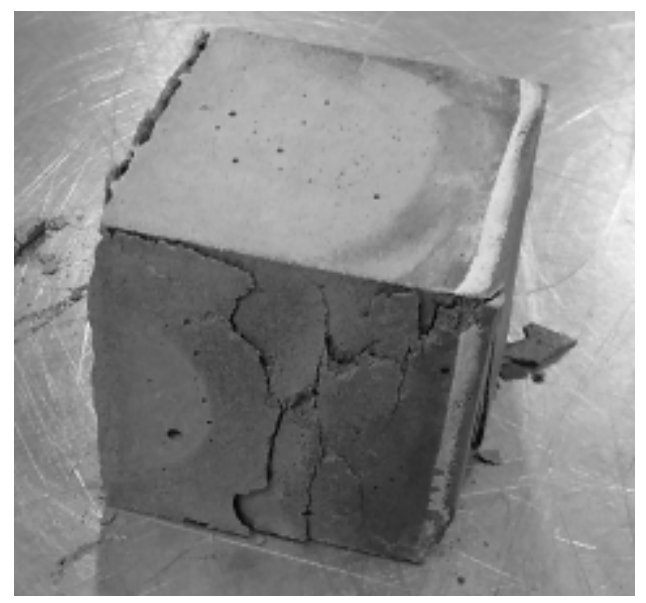

Fig. 7. The cracking pattern on broken sample.

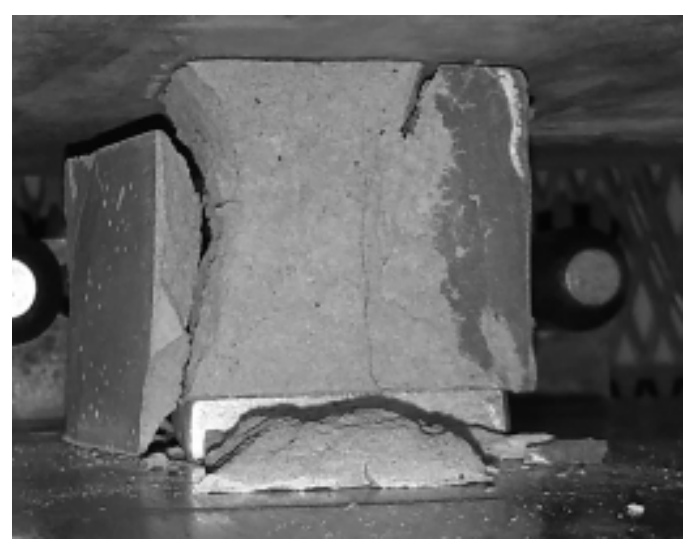

Fig. 8. Broken sample in the compression machine.

Broken parts of the sample were stiff. The amount of powder was negligible what means that process of polymerization was completed in whole structure of the sample.

The next promising feature of tested geopolymer is very low density. The average density of all six samples was equal to $14.26 \mathrm{kN} / \mathrm{m}^{3}$. This value is much lower than density of normal weight concrete. Looking at compressive strength and density of geopolymer based on the coal mine waste it can be said that this material is competitive for the structural lightweight concrete which density should range from 13.5 to $19.0 \mathrm{kN} / \mathrm{m}^{3}$ and compressive strength should be not less than 17MPa [2].

\section{Conclusions}

The two new types of geopolymer mixtures were tested. The first geopolymer based on the coal mine wastes occurred to be promising material. The second type of geopolymer based on the shale from the postmining spoil tip has worse characteristics. During the test the optimal composition for geopolymer based on the coal mine waste was defined.

The finally obtained geopolymer has good compressive strength and very low density. It can state lightweight structural building material as well as material for non structural purposes. As the advantage of tested material there should be mentioned also the fact that differences in obtained results were negligible and the fact that tested material is environmental friendly.

On the other hand, the fast polymerization process and short time of workability of geopolymer are challenges for researchers. These problems had to be solved in the future. Besides, many parameters of presented material are not known yet and have to be tested in future. Nevertheless, as it was said before, geopolymer based on the coal mine waste can possibly state in the future the building material.

\section{References}

1. US Environment Protection Agency, Design and Evaluation of Tailings dams, Technical Report (1994)

2. A.M. Neville, Właściwości betonu. Polski Cement. Kraków (2000)

3. D. Hardjito, B.V. Rangan, Development and properties of low-calcium fly ash-based geopolymer concrete. Research Report GC 1 Faculty of Engineering Curtin University of Technology, Perth, (2005)

4. J.L. Provis, J.S.J. van Deventer, Alcali Activated Materials, State-of-the-Art Report, RILEM TC224AAM (2014)

5. Z. Zhang, H. Wang, J.L. Provis, A. Reid, Efflorescence: A critical challenge for geopolymer applications? Concrete Institute of Australia's Biennial National Conference, Australia (2013)

6. European Standard EN 1992-1-1. Eurocode 2: Design of concrete structures - Part 1: General rules and rules for buildings. Brussels (2002). 